\title{
Association of Tomato Leaf Curl New Delhi Virus, Betasatellite, and Alphasatellite with Mosaic Disease of Spine Gourd (Momordica dioica Roxb. Willd) in India
}

\author{
V. Venkataravanappa ${ }^{1, *}$, C. N. Lakshminarayana Reddy ${ }^{2}$, K. S. Shankarappa ${ }^{3}$, M. Krishna Reddy ${ }^{4}$ \\ ${ }^{1}$ Central Horticultural Experiment Station (CHES), Chettalli, Indian Institute of Horticultural Research, Hessaraghatta \\ Lake PO, Bengaluru, India \\ ${ }^{2}$ Department of Plant Pathology, College of Agriculture, GKVK, University of Agricultural Sciences, Bangalore, \\ Karnataka, India \\ ${ }^{3}$ Department of Plant Pathology, College of Horticulture, Bengaluru, University of Horticultural Sciences, Bagalkot, \\ Karnataka, India \\ ${ }^{4}$ Indian Institute of Horticultural Research, Hessaraghatta Lake PO, Bangalore, Karnataka, India
}

* Corresponding author: V. Venkataravanappa, Central Horticultural Experiment Station (CHES), Chettalli, Indian Institute of Horticultural Research, Hessaraghatta Lake PO, Bengaluru, India. Tel/Fax: 08726-266300; E- mail: venkataravanappa@iihr.res.in

\begin{abstract}
Background: Spine gourd (Momordica dioica Roxb. Willd) is one of the important cucurbitaceous crops grown across the world for vegetable and medicinal purposes. Diseases caused by the DNA viruses are becoming the limiting factors for the production of spine gourd reducing its potential yield. For the commercial cultivation of the spine gourd, propagation material used by most of the growers is tuberous roots and stem cuttings, which in turn results in an increased occurrence of the mosaic disease. There is a need for understanding the causal agent; through characterization of which will lead to the designing management strategies for the spine gourd mosaic disease control. Objectives: Characterization of a begomovirus and its satellites associated with mosaic disease on spine gourd.

Materials and Methods: Total DNA was extracted from spine gourd samples exhibiting symptoms typical to the begomoviruses infection (mosaic mottling, leaf curl) and was tested by PCR using begomovirus specific primers. Furthermore, the complete genome of begomo viruses (DNA A, DNA B, alpha satellite, and beta satellite) was amplified by rolling circle amplification (RCA) method.

Results: The full-length sequences of DNA A, DNA B, alpha satellite, and beta satellite isolated from symptomatic spine gourd were determined. The full length genomes (DNA A and DNA B) of the Tomato leaf curl New Delhi Virus (ToLCNDV) infecting spine gourd were compared with the other begomovirus genomes available in the data base. The sequence analysis has revealed that DNA A and DNA B components of the begomovirus infecting spine gourd share 95.4-96.2 and 86.7-91.2\% identical sequence (i.e., nucleotide (nt) identity) with that of ToLCNDV infecting potato and cucurbits in the Indian subcontinent isolates reported earlier (available in GenBank), respectively. Further, alpha satellite and beta satellite were also detected in the begomovirus infected spine gourd samples. The recombination analysis of the DNA A, DNA B, beta satellite, and alpha satellite of the begomovirus infecting spine gourd showed the associated begomovirus and satellite DNAs were driven from the different begomoviruses, leading to emergence as a new variant of the begomovirus infecting spine gourd.

Conclusions: The commercial cultivation of the spine gourd by most growers depends on the tuberous roots and stem cutting. The occurrence of begomovirus in spine gourd gives an alarming signal against utilization of such infected plant materials in the crop breeding and improvement programs. Using the clean virus-free vegetative propagation material is considered as one of the most important methods for controlling viral diseases. The study is highly useful for detection of the begomovirus infecting spine gourd in the detection of the virus infection in the clonally propagated planting material.
\end{abstract}

Keywords: Alphasatellite; Betasatellites; Begomovirus; Recombination 


\section{Background}

Spine gourd (Momordica dioica Roxb. Willd) is a perennial, rhizomatous, dioecious, climbing creeper which belongs to the family of Cucurbitaceae and commonly is known as Kakrol. It is originated from Indo-Malayan region and distributed throughout India, China, Nepal, Bangladesh, Myanmar, Pakistan, and Sri Lanka (1). In India, the crop is being widely cultivated in Orissa, Maharashtra, Karnataka, Andhra Pradesh, Bihar, and West Bengal for its good taste and high nutritional value. Generally, spine gourd is largely cultivated through vegetative propagation and is less propagated by seeds (2). The edible fruits contain a high amount of protein, carbohydrate, fiber, moisture, ash, iron, calcium, phosphorus, thiamine, riboflavin, and niacin (3). Apart from nutritional value, all parts of spine gourd have medicinal properties to cure various diseases and disorders in human being. It has a huge demand in the market, but still remains underutilized $(4,5)$ and commercially under-exploited due to its vegetative mode of propagation, dioecious nature, low percentage of the seed germination, and a long period of seed dormancy (4). The commercial propagation of the spine gourd mainly depends on the tuberous roots followed by stem cuttings. The Spine gourd plants showing symptoms typical to the begomoviruses' infection in the cucurbits is emerging as the major constraint for its production and making the availability of the healthy planting material difficult in the country. Begomoviruses are single-stranded DNA viruses belonging to the family Geminiviridae with the morphology of geminate particles and are transmitted by the whitefly (Bemisia tabaci). Begomovirus could either have a monopartite or bipartite genome. The bipartite begomoviruses have two genome components referred to as DNA A and DNA B. The DNA A component contains five open reading frames (ORFs) encoding pre-coat protein, coat protein in the virion strand, as well as DNA replication-associated proteins in the complementary strand (6). The DNA B component contains two ORFs and encodes factors required for inter and intra-cellular movement in the host plants (7). Furthermore, based on the genome organization, genetic diversity, and geographical distribution, it has been further divided into two groups; the old world (OW) (Europe, Africa, Asia and Australia) and the new world (NW) (America) begomoviruses. The NW begomovirus is evaluated to be bipartite with lack of AV2 ORF in the DNA A component. Whereas both bipartite and monopartite begomovirus in the OW encodes AV2 ORF. The monopartite begomoviruses have a single genome analogous to the DNA A of the bipartite viruses with the association of additional ssDNA molecules known as betasatellites and/or alphasatellites (DNA1) (8). Betasatellites are approximately half the genome size of their helper begomoviruses and are required for inducing typical disease symptoms in their original hosts (9). Alphasatellites are self-replicating circular ssDNA molecules and depend on the helper virus for movement, encapsidation, vector transmission, and play no role in symptom induction (10).

\section{Objective}

Spine gourd is consumed by tribal groups living around the natural forest areas, especially at higher altitudes, where the native folks consume it as a daily vegetable. The spine gourd did not gain much popularity until it was discovered to have a high nutritional and medicinal value, which helps the development of body towards natural immunity from many common ailments. The disease caused by the begomovirus is the major constraint for production of the healthy planting material as well as its production in the country. The virus infected plants are exhibiting severe mosaic, mottling, and leaf curl symptoms. The disease incidence is ranged from 50-60\% across different farmer's fields at Varanasi, Uttar Pradesh state of India. Therefore, the current study was undertaken to characterize the probable begomovirus and its associated satellites with the mosaic disease of the spine gourd in India.

\section{Materials and Methods}

\subsection{Virus Source}

Five leaf samples of spine gourd exhibiting mosaic, mottling, leaf curl, and distortion symptoms (Fig. 1A1D) and two samples from non-symptomatic plants were collected during 2014-15 from different farmer's fields of the Varanasi, Uttar Pradesh state, India.

\subsection{DNA Isolation, PCR-Mediated Amplification, and Sequencing}

Total DNA was extracted from symptomatic and nonsymptomatic leaf samples using CTAB (11). The presence of begomovirus infection in the spine gourd was tested by PCR using begomoviruses specific degenerative primers (12). The full-length genomic DNA components were amplified from the virusinfected samples using a TempliPhi illustra amplification kit (GE Healthcare, Piscataway, NJ). The resulted rolling circle amplification (RCA) product was digested with BamH1 (DNA-A) and XbaI (DNA-B) restriction endonucleases for isolation of the monomeric units of the genome, cloned into pUC19 plasmid (13), and were transformed into the competent Escherichia coli DH5a strain. Restriction digestion was performed for confirming recombinant clones. Similarly, to identify the association of the sample with satellite genomes, the total DNA was amplified using betasatellite (DNA- $\beta$ ) (14) and alphasatellite (15) specific primers. The amplified PCR products were ligated into $\mathrm{pTZ57R/T}$ vector (INSTA cloning kit, (Thermo Fisher Scientific Inc., PA). Recombinant 
clones were identified by restriction endonuclease digestion for the presence of the cloned products. The selected clones were sequenced with an automated sequencing ABI PRISM 3730 (Applied Biosystems) at Amnion DNA Sequencing facility, Bengaluru, Karnataka, India.
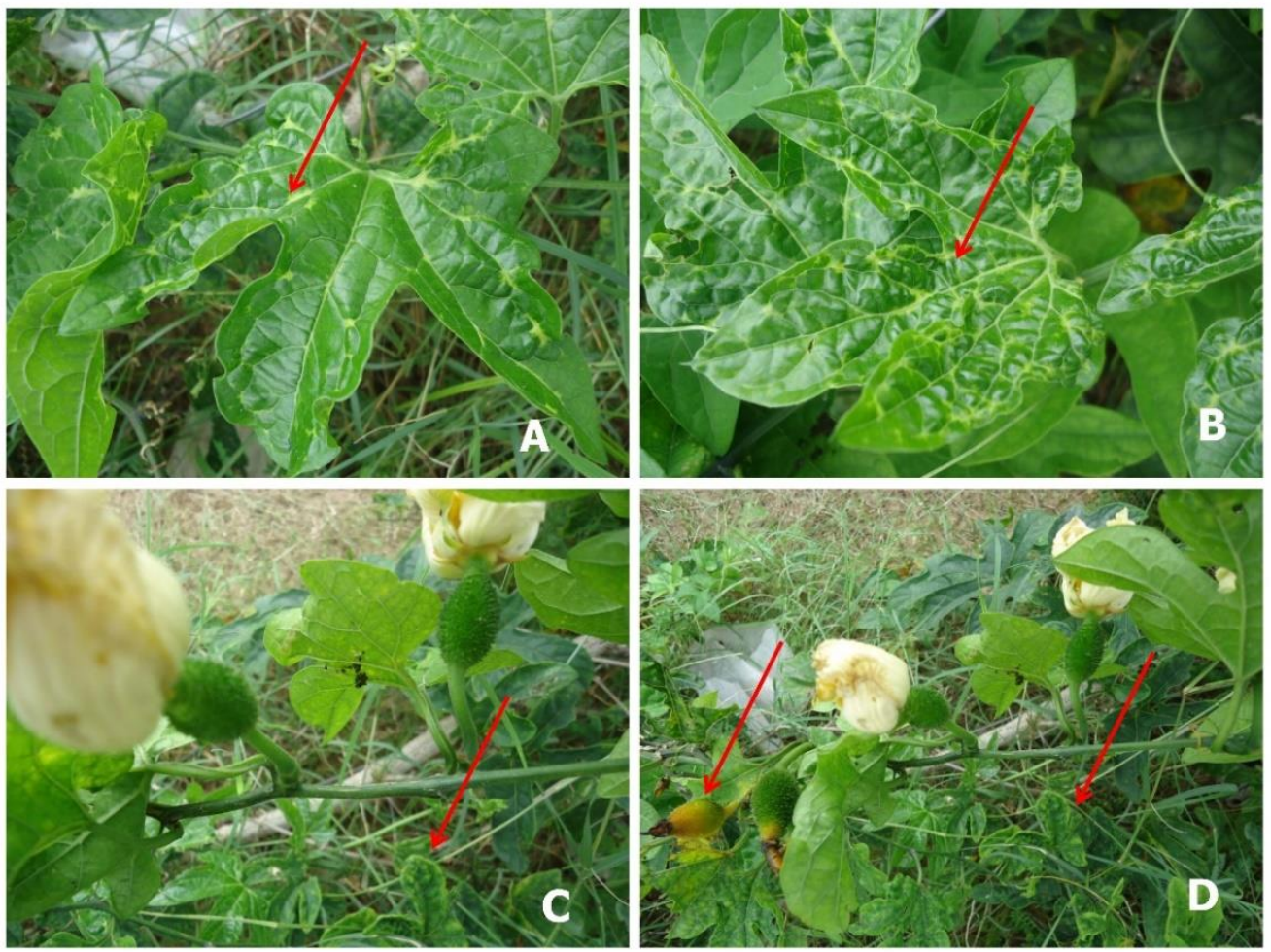

Figure 1. Spine gourd plant showing (A) a mild mosaic, (B) severe mosaic, (C) and (D) drying of the fruits under natural conditions.

\subsection{Sequence Analysis and Detection of}

Recombination Events

The sequences obtained were initially analyzed using the Vector NTI AdvanceTM 9 software to remove vector sequences. Further, the sequences were verified for the presence of all begomovirus specific Open reading frames (ORFs) using NCBI ORF finder and conserved nonanucleotide sequence. The selected begomovirus species (Table S1), betasatellites (Table S2) and alphasatellites (Table S3) accessions showing highest percentage sequence identity/similarity/ homology with the current sequences in the study were retrieved from the GenBank for analysis. The retrieved sequences were aligned with the present isolate using the MUSCLE method in SDT version 1.2 (16) and percent pair-wise nt identities were generated. The phylogenetic tree was generated by MEGA 7 software (17) using the neighbour-joining method with 1,000 bootstrapped replications to estimate evolutionary distances between all pairs of the sequences. Splitdecomposition trees were constructed with 1,000 bootstrap replicates based on parsimony splits as implemented in SplitsTree version 4.11.3 with default settings (18). Recombination analysis was carried out using the recombination detection program (RDP), GENECOV, Bootscan, Max Chi, Chimera, Si Scan, 3Seq which are integrated in the RDP4 (19). The default RDP settings with $0.05 P$-value cut off throughout and standard Bonferroni correction were used.

\section{Results}

\subsection{Genome Organization of DNA A Component of Begomovirus}

The spine gourd leaf samples showing symptoms typical to the begomovirus infection were showed positive PCR amplification to begomovirus specific primers and no amplification was observed from non-symptomatic samples. Further, the full genome components (DNA A and DNA B) were amplified and the resultant amplified products of $2.7 \mathrm{~kb}$ were cloned into pUC19 plasmid. The representative ten recombinant plasmids were sequenced and confirmed by BLAST analysis. The DNA A sequences of the five begomovirus isolates characterized from spine gourd showed 99.8-100 percent nt sequence identity among themselves indicating that they belong to a single species, based on species demarcation criteria for the begomoviruses; $91 \%$ nt sequence identity for complete genome (20). Therefore, one representative from the begomovirus isolate of SPYG1 was selected for amplification of the DNA A and DNA B as well as alpha and betasatellite of the begomovirus infecting spine gourd. 
4.2. Sequence Identities of the DNA $A$ and DNA B Components with Other Begomoviruses

The DNA A and DNA B component of the begomovirus isolate SPYG1were determined to be 2745 nt and 2696 nt in length, respectively and were deposited in the GenBank database (Accession no.: KY780213 and KY780214). The SDT analysis of the DNA A component of the isolateSPYG1 infecting spine gourd showed the highest nt identity of 95.4-96.2 per cent with the isolates of the Tomato Leaf Curl New Delhi irus (ToLCNDV) infecting potato (EF043231, EF043230, AY286316, AM850115) in the India (Table 1), which is followed by the isolates of ToLCNDV reported on cucurbits (83.8 -84.2\%), chilli (93.7-95.8\%), tomato (92.8-94.9\%), and eggplant (93.3\%) from India (Table 1). While DNA B-like sequence showed the highest level of nucleotide identity of $86.7-91.2 \%$ with the isolates of ToLCNDV infecting cucurbits crops (AM286435, AB330080, AY939924, HM989846, JN208137, KC545813, DQ020490) in the Indian subcontinent, which are summarized in the database (Table 2). Based on the current species demarcation criteria for the begomoviruses ( $91 \% \mathrm{nt}$ sequence identity among complete genome) (20), the begomovirus isolate (SPYG1) with more than 95 percent nt sequence identity with ToLCNDV-pot is considered as a variant of the ToLCNDV. This result was well supported by the phylogenetic analyses of the both DNA A and DNA B components of the SPYG1 isolate by grouping with Indian isolates of ToLCNDV infecting tomato, potato, and cucurbits crops in the India and China (Fig. 2A and 2B).

Table 1. The pairwise percent of nucleotide identities between the genomic components and amino acid sequence identities of the encoded genes from the ToLCNDV-(IN: SPYG1: Var: 15) with the components and genes of the selected begomoviruses available in the databases.

\begin{tabular}{|c|c|c|c|c|c|c|c|c|c|}
\hline \multirow[t]{2}{*}{ Begomovirus\# } & \multirow[t]{2}{*}{ Genome DNA A } & \multirow[t]{2}{*}{ IR } & \multicolumn{7}{|c|}{ Gene (percentage amino acid sequence identity) } \\
\hline & & & AV2 & $\mathbf{C P}$ & Rep & TrAP & REn & AC4 & AC5 \\
\hline ToLCNDV-Cucurbits $(14)^{*}$ & $93.6-96.1$ & $80.3-94.9$ & $86.6-95.5$ & $96.0-98.0$ & $85.1-98.0$ & $76.2-96.2$ & 78.6-94.1 & $77.5-91.3$ & $65.2-90.6$ \\
\hline ToLCNDV-Potato $(4)^{*}$ & $\underline{95.4-96.2}$ & $\underline{96.3-100}$ & $\underline{94.6-96.4}$ & $97.2-98.4$ & $95.5-96.3$ & $88.4-89.9$ & $35.2-89.7$ & $\underline{94.8-100}$ & $\underline{87.5-92.5}$ \\
\hline ToLCNDV-Tomato $(11)^{*}$ & $\overline{92.8-94.9}$ & $\overline{90.9-96.0}$ & $\overline{90.1-95.5}$ & $\overline{95.7-97.6}$ & $93.9-95.8$ & $87.7-92.8$ & $82.3-93.3$ & $\overline{86.2-91.3}$ & $67.0-90.0$ \\
\hline ToLCNDV-Chilli (4)* & $93.7-95.8$ & $92.7-96.0$ & $92.8-95.5$ & $97.2-98.0$ & $94.1-97.2$ & $90.6-96.4$ & $90.4-94.1$ & $89.6-96.5$ & $85.7-88.8$ \\
\hline ToLCNDV-Eggplant $(1)^{*}$ & 93.3 & 93.8 & 93.7 & 96.8 & 94.1 & 90.6 & 91.1 & 86.2 & - \\
\hline ToLCPaV-Tomato $(2)^{*}$ & $84.1-85.1$ & $79.2-82.1$ & $66.9-70.4$ & 90.6 & $87.4-87.7$ & 78.4 & $79.4-80.1$ & $84.4-86.2$ & 56.5 \\
\hline ToLCPaV-Cucurbits $(24)^{*}$ & $83.8-84.2$ & $77.0-81.4$ & $65.3-71.3$ & $87.1-91.4$ & $84.3-87.1$ & 72.9-78.4 & $73.7-80.8$ & 73.1-87.9 & 57.1 \\
\hline SLCCNV-Pumpkin $(5)^{*}$ & $87.0-90.4$ & $79.4-82.0$ & $90.1-91.9$ & $94.1-97.6$ & 88.9-91.9 & $67.6-69.7$ & $61.7-81.1$ & $75.8-79.3$ & $81.9-86.9$ \\
\hline $\operatorname{MYMIV}(2)$ & $66.2-67.2$ & $42.2-42.9$ & $43.3-41.5$ & $73.1-74.3$ & $70.1-70.4$ & $37.6-42.1$ & 37.5 & $27.2-28.2$ & 11.1 \\
\hline
\end{tabular}

${ }^{*}$ Numbers of sequences from the databases were used in the comparisons.

IR- Intergenic region

\#The species are indicated as, Tomato leaf curl New Delhi virus (ToLCNDV), Tomato leaf curl Palampur virus (ToLCPaV), Squash leaf curl China virus (SLCCNV), Mungbean yellow Mosaic Indian virus (MYMIV). For each column, the highest value is underlined.

Table 2. The pairwise percent of the nucleotide identities between the genomic components and amino acid sequence identities of the encoded genes from the ToLCNDV-(IN: SPYG1: Var: 15) with the components and genes of the selected begomoviruses available in the databases.

\begin{tabular}{|c|c|c|c|c|}
\hline \multirow[t]{2}{*}{ Begomovirus\# } & \multirow[t]{2}{*}{ Genomea DNA Ba $^{\mathbf{a}}$} & \multirow[t]{2}{*}{$\mathbf{I R}^{\mathbf{a}}$} & \multicolumn{2}{|c|}{ Gene (percentage amino acid sequence identity) } \\
\hline & & & BV1 $^{\mathbf{b}}$ & BC1 $^{\text {b }}$ \\
\hline ToLCNDV-Tomato (13) & $82.0-89.8$ & $51.8-86.4$ & $75.7-97.0$ & $87.3-94.3$ \\
\hline ToLCNDV-Potato (6) & $87.1-87.4$ & $77.2-84.0$ & $93.2-94.4$ & $92.1-92.8$ \\
\hline ToLCNDV-Chilli (4) & $85.0-90.0$ & $75.3-85.3$ & $93.2-94.7$ & $87.3-92.8$ \\
\hline ToLCNDV-Cucurbits (9) & $86.7-91.2$ & $64.3-86.2$ & $80.5-98.1$ & $92.1-95.0$ \\
\hline ToLCPaV-Tomato (3) & $68.5-69.1$ & $52.0-52.9$ & 78.3-79.1 & $88.2-89.6$ \\
\hline ToLCPaV-Cucurbits (12) & $68.2-68.9$ & $44.9-54.7$ & $77.9-79.1$ & $86.1-89.3$ \\
\hline SLCCNV-Pumpkin (4) & $62.1-62.7$ & $47.0-49.1$ & $72.7-72.3$ & $86.1-88.6$ \\
\hline ToLCNDV-Okra (1) & 886 & 783 & 958 & 928 \\
\hline MYMIV (2) & $41.9-42.1$ & $26.8-27.8$ & $25.0-25.2$ & $38.7-39.0$ \\
\hline
\end{tabular}

${ }^{\mathrm{a}}$ Nucleotide identity; ${ }^{\mathrm{b}}$ Amino acid identity

$\mathrm{BV} 1=$ Nuclear shuttle protein gene, $\mathrm{BC} 1=$ movement protein gene

\#The species are indicated as, Tomato leaf curl New Delhi virus (ToLCNDV), Tomato leaf curl Palampur virus (ToLCPaV), Squash leaf curl China virus (SLCCNV), Mungbean yellow Mosaic Indian virus (MYMIV). For each column, the highest value is underlined.

Table 3. The percentages of nucleotide and amino acid sequence identities between betasatellite of the spine gourd (DNA $\beta$ ) and betasatellites of other begomoviruses

\begin{tabular}{lcc}
\hline Betasatellites & Complete sequence of DNA $\boldsymbol{\beta}$ (percentage NSI) & Percentage amino acid sequence identity of $\boldsymbol{\beta C 1}$ gene \\
\hline ToLCJoB (17) & $\underline{81.7-87.0}$ & $\underline{85.7-100}$ \\
ToLCBDB (14) & $61.1-63.5$ & $38.7-61.1$ \\
ChiLCB (7) & $60.4-62.9$ & $58.7-60.3$ \\
ToLCPnB (2) & $70.6-71.7$ & $67.4-73.8$ \\
ToLCuB (2) & $61.6-63.1$ & $57.7-57.1$ \\
CroYVMB (3) & $53.7-54.5$ & $46.0-49.2$ \\
RaLCB (1) & 561 & 523 \\
\hline
\end{tabular}

${ }^{*}$ Numbers of sequences from the databases used in the comparisons.

\#The species are indicated as Tomato leaf curl Joydepur betasatellite (ToLCJoB), Tomato leaf curl Bangladesh betasatellite (ToLCBDB), Tobacco leaf curl Patna betasatellite (ToLCPnB), Tomato leaf curl betasatellite (ToLCB), Croton yellow vein mosaic betasatellite (CroYVMB), Radish leaf curl betasatellite $(\mathrm{RaLCuB})$. For each column, the highest value is underlined. 
Table4. Percentages of the nucleotide or amino acid sequence identities between alphasatellite of spine gourd and alphasatellite of the other begomoviruses

\begin{tabular}{lcc}
\hline Alphasatellites $\#$ & Complete sequence of DNAD1 (percentage NSI) & Percentage amino acid sequence identity of Rep gene \\
\hline NVLP (7) & $72.2-76.7$ & $\underline{62.5-93.9}$ \\
\hline CLCuBuVD1 (3) & $74.7-75.3$ & $\underline{93.2-93.9}$ \\
\hline AEVD1 (2) & $72.6-75.7$ & $88.5-91.7$ \\
ToCSVD1 (2) & $72.0-72.9$ & $90.0-90.1$ \\
\hline SiLCNVD1 (2) & $69.9-70.2$ & $88.2-88.5$ \\
CYTLCuD1 (3) & $69.6-70.0$ & $79.0-89.2$ \\
\hline ToLCKVD1 (1) & 76.9 & 93.9 \\
CLCuVD1 (1) & 71.2 & 86.6 \\
OLCuDD1 (1) & 74.8 & 91.1 \\
BYVMVD1 (1) & 74.9 & 91.1 \\
PaLCuVD1 (1) & 70.7 & 86.3 \\
ToLCYCNVD1 (1) & 86.9 \\
SnLCuKVD1 (1) & 69.8 & 84.4 \\
SiLCVD1 (1) & 74.5 & 90.1 \\
\hline
\end{tabular}

The species are indicated as, Nanovirus-like particle (NVLP), Cotton leaf curl Burewala alphasatellite (CLCuBuVD1), Ageratum enation alphasatellite (AEVD1), Tobacco curly shoot alphasatellite (ToCSVD1), Sida yellow vein China alphasatellite (SiLCNVD1), Cyamopsis tetragonoloba leaf curl alphasatellite (CyTLCuD1), Tomato leaf curl Karnataka alphasatellite (ToLCKVD1), Cotton leaf curl alphasatellite (CLCuVD1), Okra leaf curl virus alphasatellite (OLCuDD1), Bendhi yellow vein mosaic alphasatellite (BYVMVD1), Papaya leaf curl alphasatellite (PaLCuVD1), Tomato yellow leaf curl China virus (ToLCYCNVD1), Sunflower leaf curl Karnataka alphasatellite (SnLCuKVD1), Sida leaf curl alphasatellite (SiLCVD1).For each column, the highest value is underlined.

ORF wise, the amino acid (aa) sequence identities at the protein level showed the highest aa sequence identities with the different isolates of ToLCNDV, the regions viz. pre-coat (AV2), coat protein (CP), C4, and C5 shared maximum amino acid identity with the ToLCNDV infecting potato. Whereas, Rep (C1), TrAP (C2), and REn (C3) regions shared the most identity with the ToLCNDV infecting chilli (Table 1) in the DNA A component.

In the IR region, the identity of begomovirus (i.e., clone SPYG1) was more than $96 \%$ with the intergenic regions (IRs) of the reported ToLCNDV infecting potato isolates (Table 1). The length of IR is $275 \mathrm{nt}$ and similar to those of bipartite begomoviruses reported so far for the DNA A component.

Similarly, individually encoded proteins of the DNA B component were compared. The highest amino acid (aa) sequence similarities were found for movement protein (80.5-98.1\%) and nuclear shuttle protein (92.1$95.0 \%$ with that of ToLCNDV infecting cucurbitaceous crops (Table 2). The length of the IR is $311 \mathrm{nt}$ and similar to those of ToLCNDV isolates available in the database and shared 51.8-86.4 percent identity with the ToLCNDV isolates infecting tomato.

4.3. Genome Organization of the Alpha and Betasatellite and Sequence Affinities to Other Alpha and Betasatellite

The alphasatellite (DNA D1) and betasatellite (DNA $\beta 1$ ) isolated from infected spine gourd were determined to be $1388 \mathrm{nt}$ (Acc NO. MG571523) and $1360 \mathrm{nt}$ (Acc. NO. MG571522) in length, respectively.

The alphasatellite have a single large ORF with a coding capacity of 315 aa in the virion-sense (coordinates 891036) (21). The sequence showed the maximum nt sequence identity (76.9\%) with Tomato leaf curl Karnataka alphasatellite (ToLCKVD1, Acc. NO JX570736) (Table 4). Since the alphasatellite sequence was showing very low levels of nt sequence identity (less than $77 \%$ ) with other isolates reported earlier and there is no proposed species demarcation threshold for classification of the alphasatellites, the present alphasatellite will be named as spine gourd mosaic alphasatellite.

The phylogenetic analysis of this studied genome component shown in Figure $\mathbf{3 A}$ indicated that the alphasatellite isolated from spine gourd segregated separately from all other satellites infecting different crops. Similarly, betasatellite sequence in the current study contains all the features typical to the betasatellites reported so far $(12,14)$ and showed maximum nt identity of 81.7 to 87 percent with the tomato leaf curl Jodeypur betasatellite (ToLCJoB) isolates originating from the Indian subcontinent infecting different crops (Table 3). Based on the recently proposed species demarcation threshold for betasatellites (22), the betasatellite identified here is an isolate of ToLCJoB infecting chilli and tomato, which is well supported by phylogenetic analysis (Fig. 3B).

\subsection{Neighbor-Net and Recombination Analysis}

A neighbor-network, Pairwise Homoplasy Index (PHI) test and breakpoint analysis for the recombination was carried out for nt sequences of the different begomoviruses genomic components (DNA A, DNA B, betasatellite, and alphasatellite) along with the sequences of the virus isolated from the spine gourd. This revealed that SPYG1 isolate was evolved through recombination.

The RDP 4 analysis indicated the evidence of recombination in ToLCDNV (SPYG1) infecting spine gourd with most of the DNA A fragments derived from ToLCNDV, Squash leaf curl China virus (SLCCNV) and Tomato leaf curl Palampur virus (ToLCPaV) to emerge as a new strain of ToLCNDV infecting spine gourd (Table S4, Fig. 4). 
A

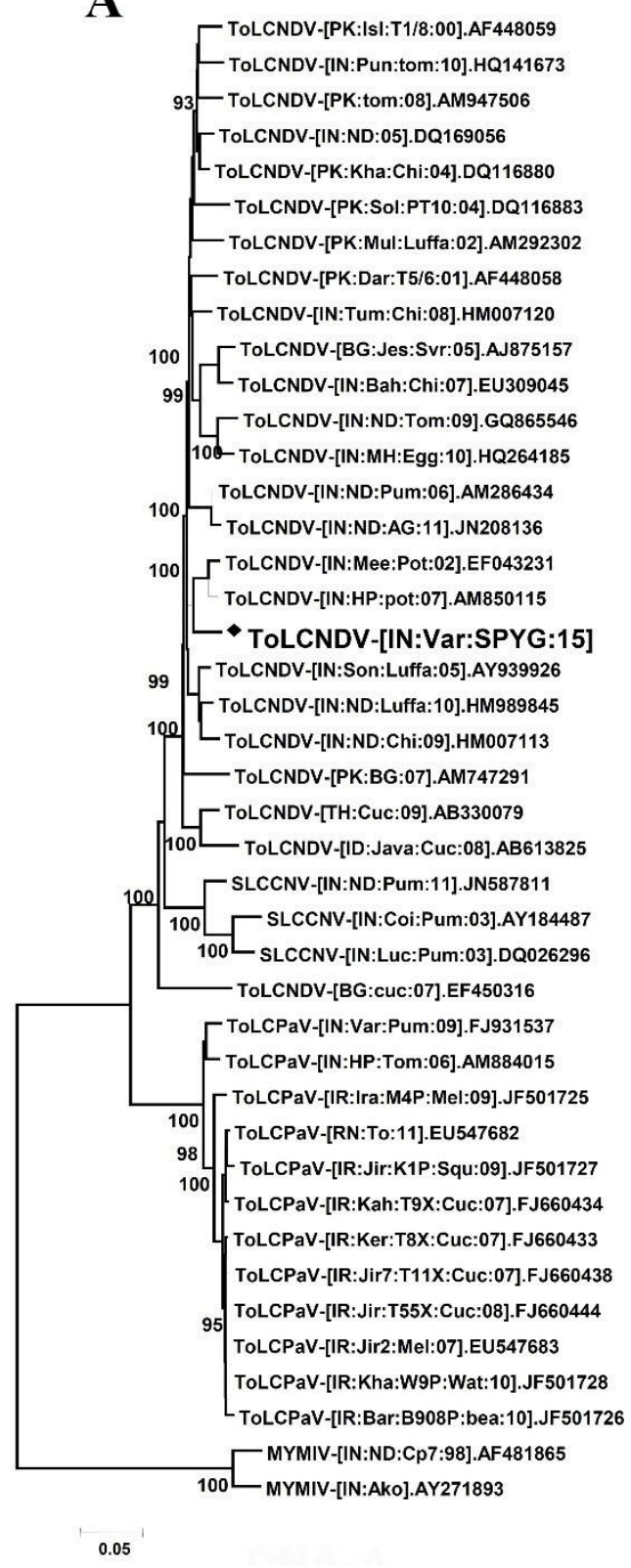

[oLCNDV-[IN:ND:Pum:06].DQ169057

B 99 ToLCNDV-[IN:ND:Iuf:10].HM98984

ToLCNDV-[IN:ND:CuC:12].KC545813

ToLCNDV-[PK:Lah:Tom:07].AM778833

99 -ToLCNDV-[IN:Son:Luf:05].AY939924

TOLCNDV-[IN:BLR:Chi:11].JN663848

100

TOLCNDV-[PK:SOl:09].FN435312

ToLCNDV-[IN:ND:Svr:92].U15017

99

ToLCNDV-[IN:ND:Tom:Svr:10].HM159455

— ToLCNDV-[IN:TN:OK:06].HQ586007

ToLCNDV-[IN:BG:ND:05].DQ020490

100

- ToLCNDV-[IN:Var:SPYG:15]

. ToLCNDV-[TH:cuc:07].AB330080

98 ToLCNDV-[IN:ND:Pum:06].AM286435

100 ToLCNDV-[IN:AG:11].JN208137

99 ToLCNDV-[IN.HR:Pot 10].KC874495

99 -ToLCNDV-[IN:PJ:Pot:13].KC874501

ToLCNDV-[IN:Mee:Po12:02].AY158080

ToLCNDV-[IN:UP:Pot:13].KC874497

— ToLCNDV-[PK:IsI:T1/8:00] AY150304

100 ToLCNDV-[PK:Kha:Chi:04].DQ116882

100 ToLCNDV-[PK:Sn:97].AJ620188

$100-$ ToLCNDV-[IN:PJ:Tom:13].KF571462
— ToLCNDV-[BD:Jess:Severe:05].AJ875158

100 ToLCPaV-[IN:PJ:Tom:13].KC456162

ToLCPaV-[IN:HP:Tom:08].AM992534

100 FoLCPaV-[IR:Roo:T10X:Tom:06].FJ660442

100 ToLCPaV-[IR:Jir:T55X:Cuc:08].FJ660443

[ ToLCPaV-[IR:Jir6:T3P:Cuc:07].FJ660427

99 ToLCPaV-[IR:Jir2:Mel:07].EU547681

-SLCCNV-[IN:Coi:Pum]. AY184488

100 SLCCNV-[IN:ND:Pum:11].JN624306

99 LLCCNV-[IN:Var:Pum:08]. FJ859881

-MYMIV-[IN:ND:Cp7:98]. AF503580

100 —MYMIV-[IN:Ako]. AY271894

Figure 2. Phylograms were constructed using the neighbour joining (NJ) method. (2A) The DNA-A sequence of the begomovirus (SPYG1 clone) and (2B) the DNA-B sequence of the begomovirus (SPYG1 clone) associated with the severe mosaic disease of the spine gourd in India. Branches corresponding to the partitions reproduced in the less than $50 \%$ bootstrap replicates are collapsed. The percentage of the replicate trees in which the associated taxa clustered together in the bootstrap test (1000 Replicates) is shown below the branches. 

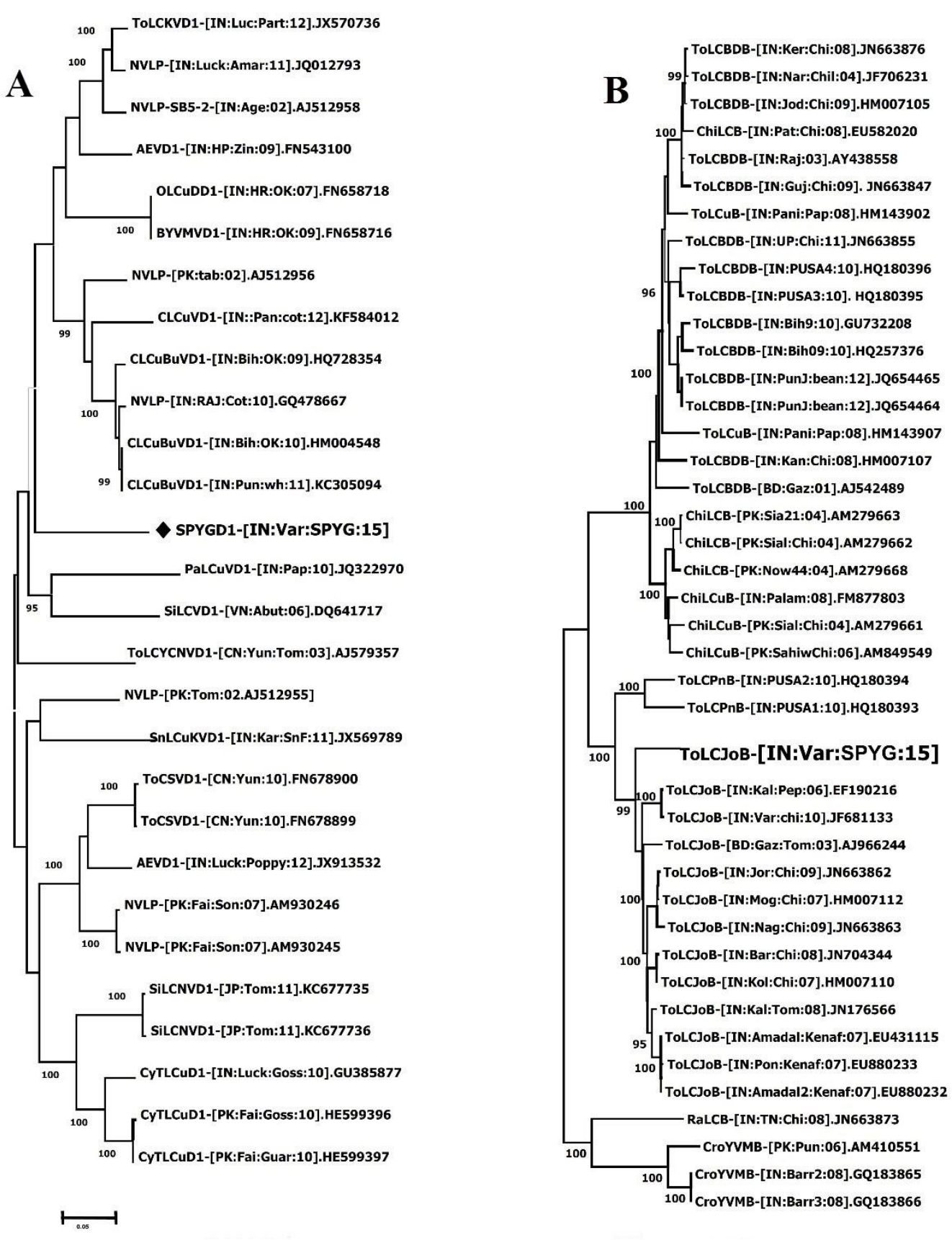

Figure 3. Phylograms were constructed from the aligned complete nucleotide sequences of (3A) Alphasatellite (DNA D1) and (3B) betasatellite $(\mathrm{DNA} \beta)$ associated with severe mosaic disease of spine gourd in India using the NJ method. The horizontal distances are proportional to the sequence distances; vertical distances are arbitrary. The trees are unrooted. A bootstrap analysis with 1000 replicates was performed and the bootstrap percent values more than 50 are numbered along branches.

In case of DNA B sequence, most part of BV1 (movement protein) and $\mathrm{BC} 1$ (nuclear shuttle protein) is derived from ToLCNDV and ToLCPaV infecting tomato, okra, and melons.The IR region is derived from the Mungbean yellow mosaic India virus (MYMIV) and ToLCNDV (Table S4, Fig. 4). The RDP analysis indicated that evidence of recombination in betasatellite suggestive of the most parts of betastallite DNA descended from Tobacco leaf curl Patna betasatellite (ToLCPnB), Tomato leaf curl Bangladesh betasatellite (ToLCBDB), and Tomato leaf curl Joydebpur betasatellite (ToLCJoB) infecting different solanaceous, and malvaceous crops in India.

The analysis of the alpha-satellite indicated that most of satellites DNA descended from Cotton leaf curl alphasatellite (CLCuVD1), Cyamopsis tetragonoloba leaf curl alphasatellite (CyTLCuD1), Okra leaf curl alphasatellite (OLCuDD1), and Sida leaf curl alphasatellite (SiLCNVD1) satellites (Table S3) are associated with cotton, guar, okra, and tomato infecting begomoviruses, respectively. 
DNA A
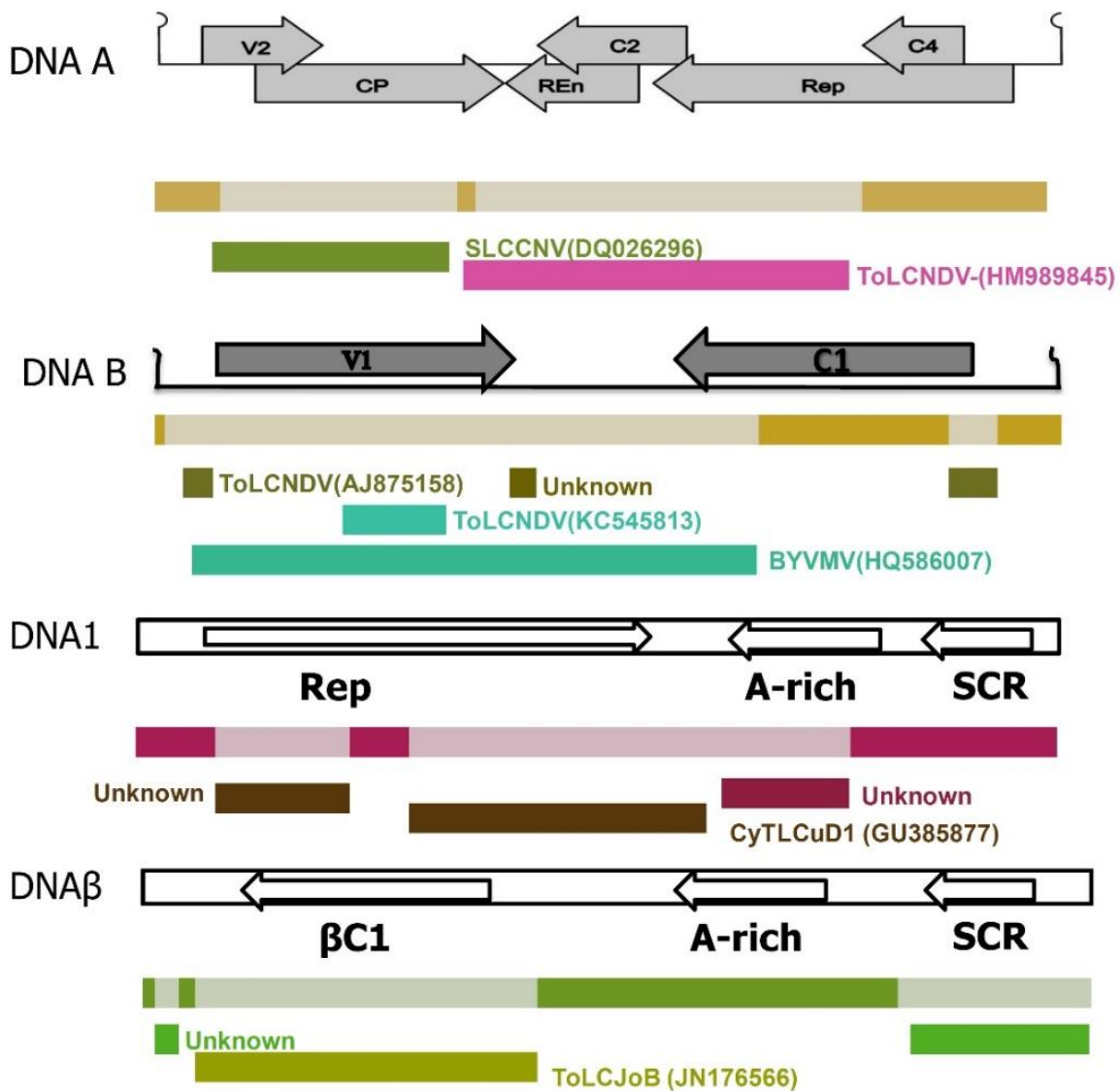

Figure 4. Analysis of recombination for ToLCNDV isolate isolated from spine gourd: The begomoviruses, alphasatllites and betasatllites acronyms given are squash leaf curl China virus (SLCCNV), tomato leaf curl new Delhi virus (ToLCNDV), cyamopsis tetragonoloba leaf curl alphasatellite (CyTLCuD1), Tomato leaf curl joydebpur betasatellite (ToLCJoB), sequence of indeterminate origin is indicated as "unknown". The box below at the top of the diagram indicates the approximate position recombination is occurring in the genome of the begomoviruses.

\section{Discussion}

Spine gourd is one of the cucurbitaceous crops and mosaic disease associated by begomoviruses is a limiting factor for its production. The ToLCNDV was initially identified on solanaceous crops in India (23), since then it has been reported across many countries and known to infect 43 plant species belong to the different families (24-26). The frequency of the newly emerging strains of the ToLCNDV on several cultivated and non-cultivated plant species are increasing in the recent years, indicating that the virus poses a serious threat to vegetables belonging to the family Cucurbitaceae, Euphorbiaceae, Solanaceae, Malvaceae and Fabaceae throughout the world (26). Generally, the betasatellites are found associated with the old world (OW) monopartite begomoviruses (10) and not in bipartite begomoviruses with the two exceptions, MYMIV (27, 28) and ToLCNDV (29) infecting mung bean and tomato, respectively in India. In the present study, for the first the time, we have characterized ToLCNDV bipartite virus with both betasatellite and alphasatellite associated with the mosaic disease of the spine gourd in India. The tripartite interaction between ToLCNDV and betasatellite in tomato was well proved through agro-inoculation of the cloned DNA A, DNA B, and betasatellites in the N. benthamiana and tomato (30). It was evident that the plants co-inoculated with DNA A, DNA B, and betasatellites will enhance the symptom severity in the $N$. benthamiana and tomato directly increases the helper viral DNA A and DNA B replication levels in the host cells.

The betasatellite associated with spine gourd mosaic disease is identified as ToLCJoB, which is also associated with the heterologous begomoviruses infecting chilli $(31,32)$, tomato (33), and kenaf (34) plants in India. The trans-replication of ToLCNDV and defective betasatellites has been shown for many distinct begomovirus species/betasatellite combinations (30, 34-36). The other bipartite begomoviruses confirmed to trans-replicate betasatellite are Sri Lankan cassava mosaic virus (36), Tomato yellow leaf curl Thailand virus (37), and the New World bipartite Cabbage leaf curl begomovirus (38). These observations clearly indicated that there is no distinct demarcation between monopartite and bipartite begomoviruses for their ability to trans-replicate betasatellites in the genome. The nt sequence of alphasatellite isolated from spine gourd showed less than 77 per cent identity with the previously reported alphasatellites, hence we proposed the name spine gourd mosaic alphasatellite. The exact role of alphasatellites has not been fully understood. 
However, alphasatellites attenuate the disease symptoms and involve in the maintenance of the low level of betasatellite accumulation (39). It was also shown that the Rep of alphasatellites can suppress RNAi pathway in monopartite begomovirus disease complexes (40). The PHI value in the present study has strongly supported the presence of recombination in SPYG1 isolate. The different methods used for recombination breakpoint analysis provided strong evidence for the presence of the past recombination events in most of the genome components. The role of such overlapping recombination between different isolates or different species in adaptation to spine gourd may be an interesting aspect that needs to be resolved. Such inter and intra-species recombinations are the predominant feature of begomovirus evolution (8) and have been implicated in the emergence of new begomovirus species and adaptation in new hosts in the agricultural system (40).

The commercial cultivation of spine gourd by most of the growers is depends on the tuberous roots and stem cutting. The occurrence of the mosaic disease on spine gourd gives an alarming signal against utilization of such virus infected planting materials in the crop breeding and improvement program. The technique developed here will be highly useful to detect the virus infection in clonally propagated plants such as spine gourd.

\section{Acknowledgements}

This research was supported by the project "Consortium platform on vaccines and diagnostics" funded by the Indian Council of Agricultural Research, Government of India, New Delhi, India.

\section{Conflicts of Interest}

The authors declare that they have no competing interests.

\section{Ethical Approval}

This article does not contain any studies with the human participants performed by any of the authors.

\section{References}

1. Trivedi RN, Roy RP. Cytological studies in some species of Momordica. Genetica. 1972;43(2):282-291. doi: $10.1007 /$ bf00123635

2. Muthu T. Establishment of an efficient Agrobacterium tumefaciens-mediated leaf disc transformation of spine gourd (Momordica dioica Roxb. ex Willd). Afr J Biotechnol 2011;10(83). doi: 10.5897/ajb11.2377

3. Singh D, Bahadur V, Singh DB, Ghosh G. Spine Gourd (Momordica Dioica): An Underutilized Vegetable with High Nutritional and Medicinal Values. Acta Horticult. 2009(809):241-249. doi: 10.17660/ActaHortic.2009.8 09.25

4. Ali M, Okubo H, Fujii T, Fujieda K. Techniques for propagation and breeding of kakrol (Momordica dioica
Roxb.). Sci Horticult. 1991;47(3-4):335-343. doi: 10.1016/0304-4238(91)90017-s

5. Bharathi L, Naik G, Singh H, Dora D. Spine gourd. In: Peter K, editor. Under utilized and underexploited horticultural crops. New Delhi: New India Publishing; 2007. p. 289-295.

6. Hanley-Bowdoin L, Settlage SB, Orozco BM, Nagar S, Robertson D. Geminiviruses: models for plant DNA replication, transcription, and cell cycle regulation. Crit Rev Biochem Mol Biol. 2000;35(2):105-140. doi: 10.1080/07352689991309162 pmid: 10821479

7. Saunders K, Bedford ID, Briddon RW, Markham PG, Wong SM, Stanley J. A unique virus complex causes Ageratum yellow vein disease. Proc Natl Acad Sci U S A. 2000;97(12):6890-6895. doi: 10.1073/pnas.97.12.68 90 pmid: 10841581

8. Lefeuvre P, Lett JM, Reynaud B, Martin DP. Avoidance of protein fold disruption in natural virus recombinants. PLoS Pathog. 2007;3(11):e181. doi: 10.1371/journal. ppat.0030181 pmid: 18052529

9. Venkataravanappa V, Reddy CN, Swaranalatha P, Jalali S, Briddon RW, Reddy MK. Diversity and phylogeography of Begomovirus-associated beta satellites of Okra in India. Virol J. 2011;8(1):555. doi: 10.1186/1743-422X-8-555 pmid: 22188644

10. Briddon RW, Stanley J. Subviral agents associated with plant single-stranded DNA viruses. Virology. 2006;344(1):198-210. doi: 10.1016/j.virol.2005.09.0 42 pmid: 16364750

11. Doyle JJ, Doyle JL, Brown AHD. Analysis of a polyploid complex in Glycine with chloroplast and nuclear DNA. Austr Syst Botany. 1990;3(1):125. doi: 10.1071/sb990 0125

12. Venkataravanappa V, Lakshminarayana Reddy CN, Jalali S, Krishna Reddy M. Molecular characterization of distinct bipartite begomovirus infecting bhendi (Abelmoschus esculentus L.) in India. Virus Genes. 2012;44(3):522-535. doi: 10.1007/s11262-012-0732y pmid: 22447131

13. Venkataravanappa V, Swarnalatha P, Reddy CNL, Chauhan N, Reddy MK. Association of recombinant Chilli leaf curl virus with enation leaf curl disease of tomato: a new host for chilli begomovirus in India. Phytoparasitica. 2016;44(2):213-223. doi: 10.1007/s12600-016-0510-9

14. Briddon RW, Bull SE, Mansoor S, Amin I, Markham PG. Universal primers for the PCR-mediated amplification of DNA beta: a molecule associated with some monopartite begomoviruses. Mol Biotechnol. 2002;20(3):315-318. doi: 10.1385/MB:20:3:315 pmid: 11936260

15. Kumar J, Kumar A, Roy JK, Tuli R, Khan JA. Identification and molecular characterization of begomovirus and associated satellite DNA molecules infecting Cyamopsis tetragonoloba. Virus Genes. 2010;41(1):118-125. doi: 10.1007/s11262-010-04827 pmid: 20405195

16. Muhire BM, Varsani A, Martin DP. SDT: a virus classification tool based on pairwise sequence alignment and identity calculation. PLoS One. 2014;9(9):e108277. doi: 10.1371/journal.pone.0108 277 pmid: 25259891

17. Kumar S, Stecher G, Tamura K. MEGA7: Molecular Evolutionary Genetics Analysis Version 7.0 for Bigger 
Datasets. Mol Biol Evol. 2016;33(7):1870-1874. doi: 10.1093/molbev/msw054 pmid: 27004904

18. Huson DH, Bryant D. Application of phylogenetic networks in evolutionary studies. Mol Biol Evol. 2006;23(2):254-267. doi: 10.1093/molbev/msj030 pmid: 16221896

19. Martin DP, Murrell B, Golden M, Khoosal A, Muhire B. RDP4: Detection and analysis of recombination patterns in virus genomes. Virus Evol. 2015;1(1):vev003. doi: 10.1093/ve/vev003 pmid: 27774277

20. Brown JK, Zerbini FM, Navas-Castillo J, Moriones E, Ramos-Sobrinho R, Silva JC, et al. Revision of Begomovirus taxonomy based on pairwise sequence comparisons. Arch Virol. 2015;160(6):1593-1619. doi: 10.1007/s00705-015-2398-y pmid: 25894478

21. Briddon RW, Bull SE, Amin I, Mansoor S, Bedford ID, Rishi N, et al. Diversity of DNA 1: a satellite-like molecule associated with monopartite begomovirusDNA beta complexes. Virology. 2004;324(2):462-474. doi: 10.1016/j.virol.2004.03.041 pmid: 15207631

22. Briddon RW, Brown JK, Moriones E, Stanley J, Zerbini $\mathrm{M}$, Zhou $\mathrm{X}$, et al. Recommendations for the classification and nomenclature of the DNA-beta satellites of begomoviruses. Arch Virol. 2008;153(4):763-781. doi: 10.1007/s00705-0070013-6 pmid: 18247103

23. Padidam M, Beachy RN, Fauquet CM. Tomato leaf curl geminivirus from India has a bipartite genome and coat protein is not essential for infectivity. J Gen Virol. 1995;76 (Pt 1)(1):25-35. doi: 10.1099/0022-1317-761-25 pmid: 7844539

24. Fortes IM, Sanchez-Campos S, Fiallo-Olive E, DiazPendon JA, Navas-Castillo J, Moriones E. A Novel Strain of Tomato Leaf Curl New Delhi Virus Has Spread to the Mediterranean Basin. Viruses. 2016;8(11):307. doi: 10.3390/v8110307 pmid: 2783 4936

25. Moriones E, Praveen S, Chakraborty S. Tomato Leaf Curl New Delhi Virus: An Emerging Virus Complex Threatening Vegetable and Fiber Crops. Viruses. 2017;9(10):264. doi: 10.3390/v9100264 pmid: 28934 148

26. Zaidi SS, Martin DP, Amin I, Farooq M, Mansoor S. Tomato leaf curl New Delhi virus: a widespread bipartite begomovirus in the territory of monopartite begomoviruses. Mol Plant Pathol. 2017;18(7):901-911. doi: 10.1111/mpp.12481 pmid: 27553982

27. Rouhibakhsh A, Malathi V, Rode J, In-Chol K, Saal B, Flachowsky H, et al. Severe leaf curl disease of cowpea-a new disease of cowpea in northern India caused by mungbean yellow mosaic virus and a satellite DNA beta. Plant Pathol 2005;54(2):259.

28. Qazi J, Ilyas M, Mansoor S, Briddon RW. Legume yellow mosaic viruses: genetically isolated begomoviruses. Mol Plant Pathol. 2007;8(4):343-348. doi: $10.1111 /$ j.1364-3703.2007.00402.x pmid: 20507 504

29. Sivalingam PN, Malathi VG, Varma A. Molecular diversity of the DNA-beta satellites associated with tomato leaf curl disease in India. Arch Virol. 2010;155(5):757-764. doi: 10.1007/s00705-0100634-z pmid: 20229326
30. Jyothsna P, Haq QM, Singh P, Sumiya KV, Praveen S, Rawat $\mathrm{R}$, et al. Infection of tomato leaf curl New Delhi virus (ToLCNDV), a bipartite begomovirus with betasatellites, results in enhanced level of helper virus components and antagonistic interaction between DNA B and betasatellites. Appl Microbiol Biotechnol. 2013;97(12):5457-5471. doi: 10.1007/s00253-0124685-9 pmid: 23306645

31. Kumar RV, Singh AK, Singh AK, Yadav T, Basu S, Kushwaha N, et al. Complexity of begomovirus and betasatellite populations associated with chilli leaf curl disease in India. J Gen Virol. 2015;96(10):3143-3158. doi: $10.1099 /$ jgv.0.000254 pmid: 26251220

32. Khan MS, Raj SK, Singh R. First report of Tomato leaf curl New Delhi virus infecting chilli in India. Plant Pathol. 2006;55(2):289-289. doi: 10.1111/j.13653059.2006.01324.x

33. Tiwari N, Singh VB, Sharma PK, Malathi VG. Tomato leaf curl Joydebpur virus: a monopartite begomovirus causing severe leaf curl in tomato in West Bengal. Arch Virol. 2013;158(1):1-10. doi: 10.1007/s00705-0121440-6 pmid: 22918555

34. Paul S, Ghosh R, Das S, Palit P, Acharyya S, Das A, et al. First report ofTomato leaf curl Joydebpur virusand associated betasatellite in kenaf (Hibiscus cannabinus) plants showing leaf curl symptoms from southern India. Plant Pathol. 2009;58(2):403-403. doi: 10.1111/j.1365-3059.2008.01929.x

35. Saunders K, Briddon RW, Stanley J. Replication promiscuity of DNA-beta satellites associated with monopartite begomoviruses; deletion mutagenesis of the Ageratum yellow vein virus DNA-beta satellite localizes sequences involved in replication. J Gen Virol. 2008;89(Pt 12):3165-3172. doi: 10.1099/vir.0.2008/0 03848-0 pmid: 19008407

36. Saunders K, Salim N, Mali VR, Malathi VG, Briddon R, Markham PG, et al. Characterisation of Sri Lankan cassava mosaic virus and Indian cassava mosaic virus: evidence for acquisition of a DNA B component by a monopartite begomovirus. Virology. 2002;293(1):6374. doi: $10.1006 /$ viro.2001.1251 pmid: 11853400

37. Guo W, Yang X, Xie Y, Cui X, Zhou X. Tomato yellow leaf curl Thailand virus-[Y72] from Yunnan is a monopartite begomovirus associated with DNAbeta. Virus Genes. 2009;38(2):328-333. doi: 10.1007/s1126 2-009-0327-4 pmid: 19165588

38. Mansoor S, Briddon RW, Bull SE, Bedford ID, Bashir A, Hussain $\mathrm{M}$, et al. Cotton leaf curl disease is associated with multiple monopartite begomoviruses supported by single DNA beta. Arch Virol. 2003;148(10): 1969-1986. doi: 10.1007/s00705-003-0149-y pmid: 14551819

39. Nawaz-ul-Rehman MS, Mansoor S, Briddon RW, Fauquet CM. Maintenance of an old world betasatellite by a new world helper begomovirus and possible rapid adaptation of the betasatellite. J Virol. 2009;83(18):9347-9355. doi: 10.1128/JVI.00795-09 pmid: 19570867

40. Wu PJ, Zhou XP. Interaction between a nanovirus-like component and the Tobacco curly shoot virus/satellite complex. Acta Biochim Biophys Sin (Shanghai). 2005;37(1):25-31. doi: 10.1093/abbs/37.1.25 pmid: 15645078 
Supplementary Table 1: Gene Bank accession numbers of selected Begomovirus sequences used in the present study for analysis

\begin{tabular}{|c|c|c|c|c|}
\hline \multirow[t]{2}{*}{ Sl.No } & \multirow[t]{2}{*}{ Begomoviruses } & \multicolumn{2}{|c|}{ Accession No. } & \multirow[t]{2}{*}{ Abbreviation } \\
\hline & & DNA-A & DNA-B & \\
\hline 1 & Tomato leaf curl New Delhi virus - [India:New Delhi:Pumpkin 2:2005] & AM286434 & AM286435 & ToLCNDV-[IN:ND:Pum2:05] \\
\hline 2 & Tomato leaf curl New Delhi virus - [India:IARI:Pumpkin:2006] & JN129254 & - & ToLCNDV-[IN::ND:Pum:06] \\
\hline 3 & Tomato leaf curl New Delhi virus - [India:New Delhi:Pumpkin 1:2005] & AM286433 & - & ToLCNDV-[IN:ND:Pum:05] \\
\hline 4 & Tomato leaf curl New Delhi virus - [India:Lucknow] & Y16421 & - & ToLCNDV-[IN:Luc:98] \\
\hline 5 & Tomato leaf curl New Delhi virus - [India:Ash gourd:2011] & JN208136 & - & ToLCNDV-[IN:Ag:11] \\
\hline 6 & Tomato leaf curl New Delhi virus - [India:Meerut:Potato:2005] & EF043231 & - & ToLCNDV-[IN:Mee:Pot:05] \\
\hline 7 & Tomato leaf curl New Delhi virus - [India:Happur:Potato:2005] & EF043230 & EF043233 & ToLCNDV-[IN:Hap:Pot:05] \\
\hline 8 & Tomato leaf curl New Delhi virus - [India:Meerut:Potato 12:2002] & AY286316 & AY158080 & ToLCNDV-[IN:Mee:Po12:02] \\
\hline 9 & Tomato leaf curl New Delhi virus - [India:Himachal:Potato:2006] & AM850115 & - & ToLCNDV-[IN:HP:Pot:06] \\
\hline 10 & Tomato leaf curl New Delhi virus - [Thailand:Cucurbit:2006] & AB330079 & AB330080 & ToLCNDV-[TH:Cuc:06] \\
\hline 11 & Tomato leaf curl New Delhi virus - [Thailand:Cucurbit:2006] & AB368448 & - & ToLCNDV-[TH:Cuc:06] \\
\hline 12 & Tomato leaf curl New Delhi virus - [Thailand:Bottle gourd:2006] & AB368447 & - & ToLCNDV-[TH:Cuc:06] \\
\hline 13 & Tomato leaf curl New Delhi virus - [Indonesia:Java:Cucumber:2008] & $\mathrm{AB} 613825$ & - & ToLCNDV-[ID:Java:Cuc:08] \\
\hline 14 & Tomato leaf curl New Delhi virus - [Bangladesh:Cucumber:2006] & EF450316 & - & ToLCNDV-[BG:cuc:06] \\
\hline 15 & Tomato leaf curl New Delhi virus - [Pakistan:Islamabad:T1/8:2000] & AF448059 & AY150304 & ToLCNDVIN[PK:Isl:T1/8:00] \\
\hline 16 & Tomato leaf curl New Delhi virus - [India:Pune:JID27:2008] & HQ141673 & HQ141674 & ToLCNDV-[IN:Pun:Tom:08] \\
\hline 17 & Tomato leaf curl New Delhi virus - [India:Pune 8:2008] & FJ468356 & - & ToLCNDV[IN:Pune:Tom:08] \\
\hline 18 & Tomato leaf curl New Delhi virus - [Pakistan:Solanum nigrum:PT10:2004] & DQ116883 & - & ToLCNDV-[PK:Sol:PT10:04] \\
\hline 19 & Tomato leaf curl New Delhi virus - [Pakistan:tomato:2008] & AM947506 & - & ToLCNDV-[PK:Tom:08] \\
\hline 20 & Tomato leaf curl New Delhi virus - [India:New Delhi:2005] & DQ169056 & DQ169057 & ToLCNDVIN[IN:ND:05] \\
\hline 21 & Tomato leaf curl New Delhi virus - [Pakistan:Dargai:T5/6:2001] & AF448058 & - & ToLCNDV-[PK:Dar:T5/6:01] \\
\hline 22 & Tomato leaf curl New Delhi virus - [India:New Delhi:2006] & EF068246 & - & ToLCNDV-[IN:ND:Tom:06] \\
\hline 23 & Tomato leaf curl New Delhi virus - [Bangladesh:Jessore:Severe:2005] & AJ875157 & AJ875158 & ToLCNDV-[BG:Jes:Svr:05] \\
\hline 24 & Tomato leaf curl New Delhi virus - [India:New Delhi:2009] & GQ865546 & - & ToLCNDV[IN:ND:Tom:09] \\
\hline 25 & Tomato leaf curl New Delhi virus - [India:Maharastra:Eggplant:2009] & HQ264185 & - & ToLCNDV[IN:MH:Egg:09] \\
\hline 26 & Tomato leaf curl New Delhi virus - [India:Sonepat:Luffa:2005] & AY939926 & AY939924 & ToLCNDV-[IN:Son:Luffa:05] \\
\hline 27 & Tomato leaf curl New Delhi virus - [India:New Delhi:Lufa acutangula:JLH13:2008] & HM989845 & HM989846 & ToLCNDV-[IN:ND:Luffa:08] \\
\hline 28 & Tomato leaf curl New Delhi virus - [Pakistan:Multan:Luffa:2004] & AM292302 & - & ToLCNDV-[PK:Mul:Luffa:04] \\
\hline 29 & Tomato leaf curl New Delhi virus - [India:Bahraich:Chilli:2006] & EU309045 & - & ToLCNDV-[IN:Bah:Chi:06] \\
\hline 30 & Tomato leaf curl New Delhi virus - [India:New Delhi:Chilli:2009] & HM007113 & - & ToLCNDV-[IN:ND:Chi:09] \\
\hline 31 & Tomato leaf curl New Delhi virus - [India:Tumkur:Chilli:2008] & HM007120 & - & ToLCNDV-[IN:Tum:Chi:08] \\
\hline 32 & Tomato leaf curl New Delhi virus - [Pakistan:Khalawal:Chilli:2004] & DQ116880 & DQ116882 & ToLCNDV-[PK:Kha:Chi:04] \\
\hline 33 & Tomato leaf curl New Delhi virus - [Pakistan:Multan:Momordica:2007] & AM747291 & - & ToLCNDV-[PK:BG:07] \\
\hline 34 & Tomato leaf curl Palampur virus - [India:Palampur:Pumpkin:2008] & FJ931537 & - & ToLCPalV[IN:Var:Pum:08] \\
\hline 35 & Tomato leaf curl Palampur virus - [India:Palampur:2007] & AM884015 & AM992534 & ToLCPalV[IN:HP:Tom:07] \\
\hline 36 & Tomato leaf curl Palampur virus - [Iran:Jiroft 1:T55X:Cucumber:2008] & FJ660444 & FJ660443 & ToLCPalV[IR:Jir:T55X:Cuc:08] \\
\hline 37 & Tomato leaf curl Palampur virus - [Iran:Kahnooj:T9X:Cucumber:2007] & FJ660434 & FJ660424 & ToLCPalV[IR:Kah:T9X:Cuc:07] \\
\hline 39 & Tomato leaf curl Palampur virus - [Iran:Kerman:T8X:Cucumber:2007] & FJ660433 & FJ668379 & ToLCPalV[IR:Ker:T8X:Cuc:07] \\
\hline 40 & Tomato leaf curl Palampur virus - [Iran:Roodan:T7X:2007] & EU547682 & FJ660442 & ToLCPalV-[IR:Roo:07] \\
\hline 41 & Tomato leaf curl Palampur virus - [Iran:Khash:W9P:Citrullus lanatus:2010] & JF501728 & - & ToLCPalV[IR:Kha:W9P:Wat:10] \\
\hline 42 & Tomato leaf curl Palampur virus - [Iran:Jiroft:T5X:Cucumis sativus:07] & JF501724 & - & ToLCPaIV[IR:Jir:T5X:Cuc:07] \\
\hline 43 & Tomato leaf curl Palampur virus - [Iran:Jiroft:T13X:Cucumis melo:2006] & JF501719 & - & ToLCPalV[IR:Jir:T13X:Me:06] \\
\hline 44 & Tomato leaf curl Palampur virus - [Iran:Jiroft:T56X:Cucumis sativus:2008] & JF501721 & - & ToLCPalV[IR:Jir:T56X:Cuc:08] \\
\hline 45 & Tomato leaf curl Palampur virus - [Iran:Jiroft 1:T1X:Cucumber:2007] & FJ660440 & - & ToLCPalV[IR:Jir:T1X:Cuc:07] \\
\hline 46 & Tomato leaf curl Palampur virus - [Iran:Jiroft 9:T7X:Cucumber:2007] & FJ660437 & FJ660435 & ToLCPalV[IR:Jir9:T7X:Cuc:07] \\
\hline 47 & Tomato leaf curl Palampur virus - [Iran:Jiroft:Melon:2007] & EU547683 & EU547681 & ToLCPalV[Jiroft:Mel:07] \\
\hline 48 & Tomato leaf curl Palampur virus - [Iran:Jiroft 4:T6X:Cucumber:2007] & FJ660436 & FJ660429 & ToLCPalV[IR:Jir5:T6X:Cuc:07] \\
\hline 49 & Tomato leaf curl Palampur virus - [Iran:Jiroft 8:T58P:Cucumber:2007] & FJ660431 & FJ660425 & ToLCPalV[IR:Jir8:T58P:Cuc:07] \\
\hline 50 & Tomato leaf curl Palampur virus - [Iran:Jiroft 3:T4X:Cucumber:2007] & FJ660439 & FJ660430 & ToLCPalV[IR:Jir3:T4X:Cuc:07] \\
\hline 51 & Tomato leaf curl Palampur virus - [Iran:Jiroft 5:T51X:Cucumber:2007] & FJ660432 & FJ660428 & ToLCPalV[IR:Jir5:T51X:Cuc:08] \\
\hline 52 & Tomato leaf curl Palampur virus - [Iran:Iranshahr:M4P:Cucumis melo:2009] & JF501725 & - & ToLCPalV[IR:Ira:M4P:Mel:09] \\
\hline 53 & Tomato leaf curl Palampur virus - [Iran:Jiroft:T65X:Cucumis sativus:2008] & JF501720 & - & ToLCPalV[IR:Jir:T65X:Cuc:08] \\
\hline 54 & Tomato leaf curl Palampur virus - [Iran:Jiroft 6:T3X:Cucumber:2007] & FJ660441 & FJ660427 & ToLCPalV[IR:Jir6:T3X:Cuc:07] \\
\hline 55 & Tomato leaf curl Palampur virus - [Iran:Jiroft 7:T11X:Cucumber:2007] & FJ660438 & FJ660426 & ToLCPalV[IR:Jir7:T11X:Cuc:07] \\
\hline 56 & Tomato leaf curl Palampur virus - [Iran:Jiroft:T61X:Cucumis sativus:2008] & JF501723 & - & ToLCPalV[IR:Jir:T61X:Cuc:08] \\
\hline 57 & Tomato leaf curl Palampur virus - [Iran:Jiroft:T69P:Cucumis sativus:2008] & JQ825226 & - & ToLCPalV[IR:Jir:T69P:Cuc:08] \\
\hline 58 & Tomato leaf curl Palampur virus - [Iran:Jiroft:T63X:Cucumis sativus:2008] & JF501722 & - & ToLCPalV-[IR:Jir:T63X:Cuc:08] \\
\hline 59 & Tomato leaf curl Palampur virus - [Iran:Jiroft:K1P:Cucurbita pepo:2009] & JF501727 & - & ToLCPalV-[IR:Jir:K1P:Squ:09] \\
\hline 60 & Tomato leaf curl Palampur virus - [Iran:Barantin:B908P:Phaseolus vulgaris:2010] & JF501726 & - & ToLCPalV-[IR:Bar:B908P:Pv:10] \\
\hline 61 & Mungbean yellow mosaic India virus - [India:New Delhi:Cowpea 7:1998] & AF481865 & AF503580 & MYMIV-[IN:ND:Cp7:98] \\
\hline 62 & Mungbean yellow mosaic India virus - [India:Akola] & AY271893 & AY271894 & MYMIV-[IN:Ako] \\
\hline 63 & Squash leaf curl China virus - [India:pumpkin:IARI:2010] & JN587811 & - & SLCCNV-[IN:ND:Pum:10] \\
\hline 64 & Squash leaf curl China virus - India [India:Varanasi:Pumpkin:2008] & EU573715 & FJ859881 & SLCCNV-[IN:Var:Pum:08] \\
\hline 65 & Squash leaf curl China virus - India [India:Coimbatore:Pumpkin:2003] & AY184487 & AY184488 & SLCCNV-[IN:Coi:Pum:03] \\
\hline 66 & Squash leaf curl China virus - India [India:Lucknow:Pumpkin:2003] & DQ026296 & - & SLCCNV-[IN:Luc:Pum:03] \\
\hline 67 & Squash leaf curl China virus - India [India:Varanasi:Pumpkin2:2008] & GU967381 & GU967382 & SLCCNV[IN:Var:Pum:08] \\
\hline 68 & Tomato leaf curl New Delhi virus - [India: Ash gourd:2011] & - & JN208137 & ToLCNDV[IN:AG:11] \\
\hline 69 & Tomato leaf curl New Delhi virus - [India: New Delhi:Cucucmber:2012] & - & KC545813 & ToLCNDV-[IN:ND:Cuc:12] \\
\hline 70 & Tomato leaf curl New Delhi virus - [India:Bangalore:Chilli::2011] & - & JN663848 & ToLCNDV-[IN:BLR:Chi:11] \\
\hline 71 & Tomato leaf curl New Delhi virus - [India:Bangalore:Chilli::2011] & - & JN663867 & ToLCNDV-[IN:BLR:Chi:11] \\
\hline 72 & Tomato leaf curl New Delhi virus - [India:New Delhi:Severe:1992] & - & U15017 & ToLCNDVIN[IN:ND:Svr:92] \\
\hline 73 & Tomato leaf curl New Delhi virus - [India:Palampur:Chilli::2011] & - & JN663871 & ToLCNDV-[IN:Pal:Chi:11] \\
\hline 74 & Tomato leaf curl New Delhi virus - [Pakistan:Solanum nigrum:2009] & - & FN435312 & ToLCNDV-[PK:Sol:09] \\
\hline 75 & Tomato leaf curl New Delhi virus - [India:2009] & - & HM159455 & ToLCNDV-[IN:09] \\
\hline 76 & Tomato leaf curl New Delhi virus - [India:Tamil Nadu:Okra::2006] & - & HQ586007 & ToLNDV-[IN:TN:OK:06] \\
\hline 77 & Tomato leaf curl New Delhi virus - [India:West Bengal:Tomato::2013] & - & KF577604 & ToLCNDV-[IN:WB:Tom:13] \\
\hline 78 & Tomato leaf curl New Delhi virus - [India:Gujarat:Potato:2013] & - & KC874498 & ToLCNDV-[IN:Guj:Pot:13] \\
\hline 79 & Tomato leaf curl New Delhi virus - [India:Haryana:Potato:2010] & - & KC874495 & ToLCNDV-[IN:HR:Pot:10] \\
\hline 80 & Tomato leaf curl New Delhi virus - [India:Punjab:Potato:2013] & - & KC874501 & ToLCNDV-[IN:PJ:Pot:13] \\
\hline
\end{tabular}


81 Tomato leaf curl New Delhi virus - [India: Maharashtra :Tomato:2010]

82 Tomato leaf curl New Delhi virus - [India: Uttar Pradesh:Potato:2013]

83 Tomato leaf curl New Delhi virus - [India: New Delhi: Bitter Gourd:2005]

84 Tomato leaf curl New Delhi virus - [Pakistan:Lahore:2004]

85 Tomato leaf curl New Delhi virus - [Pakistan:Lahore:2004]

86 Tomato leaf curl New Delhi virus - [Pakistan:Solanum nigrum:1997]

Tomato leaf curl New Delhi virus - [India:Punjab:Tomato:2013]

Tomato leaf curl Palampur virus - [India:Punjab:Tomato:2013]

Tomato leaf curl Palampur virus - [Iran:Jiroft:T63X:Cucumis sativus:2008]

Squash leaf curl China virus - India [India: New Delhi:Pumpkin:11]
AM392426

AJ620188

KF571462

KC456162

FJ660423 JN624306
ToLCNDV-[IN:MH:Tom:10]

ToLCNDV-[IN:UP:Pot:13]

ToLCNDV-[IN:ND: BG:05]

ToLCNDV-[PK:Lah:04]

ToLCNDV-[PK:Lah:04]

ToLCNDV-[PK:Sn:97]

ToLCNDV-[IN:PJ:Tom:13]

ToLCPalV-[IN:PJ:Tom:13]

ToLCPalV-[IR:Jir1:T55P:Cuc:08] SLCCNV-[IN:ND:Pum:11]

Supplementary Table 2: Gene Bank accession Numbers of selected Betasatellites Sequences from Asia used in this Study for Analysis

\begin{tabular}{|c|c|c|c|}
\hline SI.No & Betasatellites & Accession numbers & Abbreviation \\
\hline $\mathbf{1}$ & Tomato leaf curl Joydebpur betasatellite -[Bangladesh:Gazipur:2005] & AJ966244 & ToLCJoB-[BD:Gaz:05] \\
\hline 2 & Tomato leaf curl Joydebpur betasatellite-[India: Jorehat:Chilli:2009] & JN663862 & ToLCJoB-[IN:Jor:Chi:09] \\
\hline 3 & Tomato leaf curl Joydebpur betasatellite-[India:Mograhat:Chilli:2007] & HM007112 & ToLCJoB-[IN:Mog:Chi:07] \\
\hline 4 & Tomato leaf curl Joydebpur betasatellite-[India:Amadalavalasa 1:Kenaf:2007] & EU431115 & ToLCJoB-[IN:Amadal:Kenaf:07] \\
\hline 5 & Tomato leaf curl Joydebpur betasatellite-[India:Kolkata:Chilli:2007] & HM007110 & ToLCJoB-[IN:Kol:Chi:07] \\
\hline 6 & Tomato leaf curl Joydebpur betasatellite-[India:Ponduru:Kenaf:2007] & EU880233 & ToLCJoB-[IN:Pon:Kenaf:07] \\
\hline 7 & Tomato leaf curl Joydebpur betasatellite-[India: Baruipur:chilli:2008] & JN704344 & ToLCJoB-[IN:Bar:Chi:08] \\
\hline 8 & Tomato leaf curl Joydebpur betasatellite-[India; Nagpur:Chilli:2009] & JN663863 & ToLCJoB[IN:Nag:Chi:09] \\
\hline 9 & Tomato leaf curl Joydebpur betasatellite-[India: Kolkata:Tomato:2008] & JN176566 & ToLCJoB-[IN:Kal:Tom:08] \\
\hline 10 & Tomato leaf curl Joydebpur betasatellite-[India: Kalyani:Pepper:2006] & EF190216 & ToLCJoB-[IN:Kal:Pep:06] \\
\hline 11 & Tomato leaf curl Joydebpur betasatellite-[India:Varanasi:Chilli:2010] & JF681133 & ToLCJoB-[IN:Var:Chi:10] \\
\hline 12 & Tomato leaf curl Joydebpur betasatellite-[India:Jodhpur:Chilli:2009] & HM007105 & ToLCBB-[IN:Jod:Chi:09] \\
\hline 13 & Tomato leaf curl Bangladesh betasatellite [India:Rajasthan:2003] & AY438558 & ToLCBDB-[IN:Raj:03] \\
\hline 14 & Chilli leaf curl betasatellite [Pakistan:Sialkot21:2004] & AM279663 & ChiLCB-[PK:Sia21:04] \\
\hline 15 & Tomato leaf curl Bangladesh betasatellite-[India:Uttar Pradesh:Chilli:2011] & JN663855 & ToLCBDB-[IN:UP:Chi:11] \\
\hline 16 & Tomato leaf curl Bangladesh betasatellite-[India:Kerela:Chilli:2011] & JN663876 & ToLCBDB-[IN:Ker:Chi:08] \\
\hline 17 & Tomato leaf curl Bangladesh betasatellite-[India:Bihar:2010] & GU732208 & ToLCBDB-[IN:Bih9:10] \\
\hline 18 & Tobacco leaf curl Patna betasatellite -[India:PUSA2:2010] & HQ180394 & ToLCPnB-[IN:PUSA2:10] \\
\hline 19 & Chilli leaf curl betasatellite- [Pakistan:Sialkot:Chilli:2004] & AM279662 & ChiLCB-[PK:Sial:Chi:04] \\
\hline 20 & Tomato leaf curl Bangladesh betasatellite-[India:Gujarat:Chilli:09] & JN663847 & ToLCBDB-[IN:Guj:Chi:09] \\
\hline 21 & Tomato leaf curl Bangladesh betasatellite[Bangladesh:Gazipur:2001] & AJ542489 & ToLCBDB-[BD:Gaz:01] \\
\hline 22 & Tomato leaf curl Joydebpur betasatellite-[India:Amadalavalasa2:Kenaf:2007] & EU880232 & ToLCJoB-[IN:Amadal2:Kenaf:07] \\
\hline 23 & Tomato leaf curl Bangladesh betasatellite -[India: Nar:Chilli:2004] & JF706231 & ToLCBDB-[IN:Nar:Chil:04] \\
\hline 24 & Chili leaf curl betasatellite-India:Pataudi:Chilli:2008] & EU582020 & ChiLCB[IN:Pat:Chi:08] \\
\hline 25 & Tomato leaf curl Bangladesh betasatellite -[India:PUSA4:2010] & HQ180396 & ToLCBDB-[IN:PUSA4:10] \\
\hline 26 & Tomato leaf curl Bangladesh betasatellite -[ India:PUSA3:2010] & HQ180395 & ToLCBDB-[IN:PUSA3:10 \\
\hline 27 & Chilli leaf curl betasatellite [Pakistan:Nowshera44:2004] & AM279668 & ChiLCB-[PK:Now44:04] \\
\hline 28 & Tomato leaf curl Joydebpur betasatellite-[India:Ponduru:Kenaf:2007] & EU880233 & ToLCJoB-[IN:Pond:Kenaf:07] \\
\hline 29 & Tomato leaf curl Bangladesh betasatellite-[India:Bihar:Bih09:2010] & HQ257376 & ToLCBDB-[IN:Bih09:10] \\
\hline 30 & Tomato leaf curl betasatellite-[India:Panipat:Papaya:2008] & HM143907 & ToLCuB-[IN:Pani:Pap:08] \\
\hline 31 & Tomato leaf curl betasatellite-[India:Panipat:Papaya:2008] & HM143902 & ToLCuB-[IN:Pani:Pap:08] \\
\hline 32 & Tomato leaf curl Bangladesh betasatellite-[India:Punjab:Beans:2012] & JQ654465 & ToLCBDB-[IN:PunJ:Bean:12] \\
\hline 33 & Tomato leaf curl Bangladesh betasatellite-[India:Punjab:Beans:2012] & JQ654464 & ToLCBB-[IN:PunJ:Bean:12] \\
\hline 34 & Tobacco leaf curl Patna betasatellite-[India:Pusa 2:2010] & HQ180393 & ToLCPnB-[IN:PUSA1:10] \\
\hline 35 & Tomato leaf curl Bangladesh betasatellite-[India:Kanpur:Chilli:2008] & HM007107 & ToLCBDB-[IN:Kan:Chi:08] \\
\hline 36 & Croton yellow vein mosaic betasatellite-[India:Barrackpore2:2008] & GQ183865 & CroYVMB-[IN:Bar2:08] \\
\hline 37 & Croton yellow vein mosaic betasatellite[India:Barrackpore3:2008] & GQ183866 & CroYVMB-[IN:Barrack:08] \\
\hline 38 & Chilli leaf curl betasatellite-[India:Palampur:2008] & FM877803 & ChiLCuB-[IN:Palam:08] \\
\hline 39 & Chili leaf curl betasatellite-[Pakistan:Sialkot:Chilli:2004] & AM279661 & ChiLCuB-[PK:Sial:Chi:04] \\
\hline 40 & Chili leaf curl betasatellite-[Pakistan:Sahiwal:Chilli:06] & AM849549 & ChiLCuB-[PK:Sahiw;Chi:06] \\
\hline 41 & Croton yellow vein mosaic betasatellite-[Pakistan:Punjab:2006] & AM410551 & CroYVMB-[PK:Pun:06] \\
\hline 42 & Radish leaf curl betasatellite-[India:Tamil Nadu:Chilli:2008] & JN663873 & RaLCB-[IN:TN:Chi:08] \\
\hline
\end{tabular}


Supplementary Table 3: Gene Bank Accession Numbers of selected Alphasatellites Sequences from Asia used in this Study for Analysis

\begin{tabular}{|c|c|c|c|}
\hline Sl.No & Alphasatellites & $\begin{array}{c}\text { Accession } \\
\text { numbers }\end{array}$ & Abbreviation \\
\hline $\mathbf{1}$ & Nanovirus-like particle-[India: Ageratum conyzoides:02] & AJ512958 & NVLP-SB5-2[IN:Age:02] \\
\hline 2 & $\begin{array}{l}\text { Tomato leaf curl Karnataka alphasatellite -[India:Lucknow:Parthenium } \\
\text { hysterophorus:2012] }\end{array}$ & JX570736 & ToLCKVD1-[IN:Luc:PaR:12] \\
\hline 3 & Nanovirus-like particle-[India:Lucknow:Amaranthus cruentus:2011] & JQ012793 & NVLP-[IN:Luc:Amar:11] \\
\hline 4 & Cotton leaf curl Burewala alphasatellite-[India:Bihar:Okra:2009] & HQ728354 & CLCuBuVD1-[IN:Bih:Okra:09] \\
\hline 5 & Cotton leaf curl Burewala alphasatellite-[India:Bihar:Okra:2009] & HM004548 & CLCuBuVD1-[IN:Bih:Okra:10] \\
\hline 6 & Cotton leaf curl Burewala alphasatellite-[India: Punjab:Wheat:2011] & КС305094 & CLCuBuVD1-[IN:Pun:Wheat:11] \\
\hline 7 & Nanovirus-like article[India:Rajasthan:Cotton:2010] & GQ478667 & NVLP-[IN:Raj:Cot:10] \\
\hline 8 & Nanovirus-like particle- [Pakistan:Tobacco:2002] & AJ512956 & NVLP-[PK:Tob:02] \\
\hline 9 & Ageratum enation virus-[India:Himachal Pradesh:Zinnia sp:2009] & FN543100 & AEVD1-[IN:HP:Zinnia sp:09] \\
\hline 10 & Nanovirus-like particle-[ Pakistan:Tomato:2002] & AJ512955 & NVLP-[PK:Tom:02] \\
\hline 11 & Nanovirus-like particle-[Pakistan:Faisalabd:Sonchus arvensis:07] & AM930246 & NVLP-[PK:Fai:Son:07] \\
\hline 12 & Nanovirus-like particle-[Pakistan:Faisalabd :Sonchus arvensis:07] & AM930245 & NVLP-[PK:Fai:Son:07] \\
\hline 13 & Tobacco curly shoot alphasatellite-[China:Yunnan:2010] & FN678900 & ToCSVD1-[CN:Yun:10] \\
\hline 14 & Tobacco curly shoot alphasatellite-[China:Yunnan:2010] & FN678899 & ToCSVD1-[CN:Yun:10] \\
\hline 15 & Okra leaf curl virus alphasatellite [India:Haryana:2007] & FN658718 & OLCuDD1-[IN:HR:Okra:07] \\
\hline 16 & Bendhi Yellow Vein Mosaic alphasatellite[India:Haryana:Okra:2009] & FN658716 & BYVMVD1-[IN:HR:Okra:09] \\
\hline 17 & Sida yellow vein China alphasatellite-[Japan:Tomato:2011] & KC677735 & SiLCNVD1-[Japan:Tom:11] \\
\hline 18 & Sida yellow vein China alphasatellite-[Japan:Tomato:2011] & KC677736 & SiLCNVD1-[Japan:Tom:11] \\
\hline 19 & Cotton leaf curl alphasatellite-[India::Panjab:Cotton:2012] & KF584012 & CLCuVD1-[IN::Pan:Cot:12] \\
\hline 20 & Guar leaf curl alphasatellite-[Pakistan:Faisalabad:Gossypium sp:2010] & HE599396 & CyTLCuD1-[PK:Fai:Guar:10] \\
\hline 21 & Guar leaf curl alphasatellite-[Pakistan:Faisalabad:Gossypium sp:2010] & HE599397 & CyTLCuD1-[PK:Fai:Guar:10] \\
\hline 22 & Ageratum enation alphasatellite-[India:Lucknow:Poppy:2012] & JX913532 & AEVD1-[IN:Luck:Poppy:12] \\
\hline 23 & Guar leaf curl alphasatellite-[India:Lucknow:Cyamopsis tetragonoloba:2010] & GU385877 & CyTLCuD1-[IN:Luck:Guar:10] \\
\hline 24 & Papaya leaf curl alphasatellite-[India:Papaya:2010] & JQ322970 & PaLCuVD1-[IN:Pap:10] \\
\hline 25 & Tomato yellow leaf curl China alphasatellite-[China:Yunnan:Tomato:03] & AJ579357 & $\begin{array}{l}\text { ToLCYCNVD1- } \\
{[\mathrm{CN}: \text { Yunnan:Tom:03] }}\end{array}$ \\
\hline 26 & Sunflower leaf curl Karnataka alphasatellite-[India:Karnataka:Sunflower:2011] & JX569789 & SnLCuKVD1-[IN:Kar:SnF:11] \\
\hline 27 & Sida leaf curl alphasatellite [Viet Nam:Thanhhoa:Abutilon indicum:2006 & DQ641717 & SiLCVD1-[V N:Than:Abu:06] \\
\hline
\end{tabular}

Supplementary Table 4: Details of recombination between ToLCNDV infecting spine gourd and other begomoviruses detected using RDP4.

\begin{tabular}{|c|c|c|c|c|c|c|c|c|}
\hline \multirow[b]{2}{*}{ Break point begin-end a } & \multicolumn{2}{|c|}{ Parent-like sequences } & \multicolumn{6}{|c|}{ P-Values } \\
\hline & Major Parent & Minor parent & RDP & $\begin{array}{l}\text { GENECO } \\
V\end{array}$ & Max Chi & Chimera & Si Scan & 3Seq \\
\hline \multicolumn{9}{|c|}{ DNA-A } \\
\hline $139-1080$ (IR, CP) & $\begin{array}{l}\text { ToLCPaV[IN:HP:Tom:06].AM8840 } \\
15\end{array}$ & $\begin{array}{c}\text { SLCCNV- } \\
\text { [IN:Luc:Pum:03].DQ02629 } \\
6\end{array}$ & $\begin{array}{c}1.636 \times 10- \\
9\end{array}$ & $\begin{array}{c}1.214 \times 10 \\
-11\end{array}$ & $\begin{array}{c}1.085 \times 10 \\
-5\end{array}$ & $\begin{array}{c}1.187 \times 10 \\
-7\end{array}$ & $\begin{array}{c}2.113 \times 10 \\
-18\end{array}$ & $\begin{array}{c}5.486 \times 10 \\
-3\end{array}$ \\
\hline 719-2338 (CP, AC3, AC2) & $\begin{array}{c}\text { ToLCNDV- } \\
\text { [IN:HP:pot:07].AM850155 }\end{array}$ & $\begin{array}{c}5 \text { ToLCNDV- } \\
\text { [IN:ND:Luffa:10].HM98984 }\end{array}$ & $\begin{array}{c}3.625 \times 10- \\
7\end{array}$ & NS & NS & NS & $\begin{array}{c}8.106 \times 10 \\
-9\end{array}$ & $\begin{array}{c}1.348 \times 10 \\
-14\end{array}$ \\
\hline \multicolumn{9}{|l|}{ DNA-B } \\
\hline 2819-141 (IR) & MYMIV-[IN:ND:Cp7:98].AF503580 & $\begin{array}{c}\text { ToLCNDV- } \\
\text { [BD:Jess:Severe:05].AJ875 } \\
158\end{array}$ & NS & NS & $\begin{array}{c}1.191 \times 10 \\
-2\end{array}$ & $\begin{array}{c}9.49 \times 10- \\
2\end{array}$ & NS & NS \\
\hline 1474-1595 (BV1) & $\begin{array}{c}\text { ToLCNDV- } \\
\text { [IN:WB:Tom:13].KF577604 }\end{array}$ & $\begin{array}{c}\text { ToLCPaV- } \\
\text { [IR:Jir2:Mel:07].EU547681 }\end{array}$ & $\begin{array}{c}1.148 \times 10- \\
10\end{array}$ & $\begin{array}{c}1.483 \times 10 \\
-3\end{array}$ & $\begin{array}{c}4.589 \times 10 \\
-2\end{array}$ & $\begin{array}{c}9.029 \times 10 \\
-4\end{array}$ & NS & NS \\
\hline 40-2522 (BV1, BC1) & $\begin{array}{c}\text { ToLCPaV- } \\
\text { [IR:Roo:T10X:Tom:06].FJ660442 }\end{array}$ & $\begin{array}{c}\text { ToLCNDV- } \\
\text { [IN:TN:OK:06].HQ586007 } \\
\text { DNAD1(Alphasat }\end{array}$ & ite) & NS & $\begin{array}{c}6.969 \times 10 \\
-1\end{array}$ & NS & $\begin{array}{c}2.721 \times 10 \\
-38\end{array}$ & NS \\
\hline 33-100 (SCR) & $\begin{array}{c}\text { CLCuVD1- } \\
{[\text { IN::PJ:Cot:12].KF584012 }}\end{array}$ & $\begin{array}{c}\text { CyTLCuD1- } \\
\text { [IN:Luck:Guar:10].GU3858 } \\
77\end{array}$ & $\begin{array}{c}1.071 \times 10- \\
3\end{array}$ & $\begin{array}{c}2.796 \times 10 \\
-3\end{array}$ & NS & NS & NS & $\begin{array}{c}3.42 \times 10 \\
2\end{array}$ \\
\hline 907-1200 (Rep) & $\begin{array}{c}\text { OLCuDD1- } \\
\text { [IN:HR:Okra:07].FN658718 }\end{array}$ & $\begin{array}{c}\text { SiLCNVD1- } \\
\text { [Japan:Tom:11].KC677735 }\end{array}$ & $\begin{array}{c}1.038 \times 10- \\
3\end{array}$ & NS & $\begin{array}{c}7.012 \times 10 \\
-3\end{array}$ & $\begin{array}{c}3.499 \times 10 \\
-3\end{array}$ & $\begin{array}{c}2.274 \times 10 \\
-6\end{array}$ & $\begin{array}{c}1.724 \times 10 \\
-2\end{array}$ \\
\hline 475-1027 (Rep) & $\begin{array}{c}\text { OLCuDD1- } \\
\text { [IN:HR:Okra:07].FN658718 }\end{array}$ & $\begin{array}{c}\text { CyTLCuD1- } \\
\text { [IN:Luck:Guar:10].GU3858 } \\
77\end{array}$ & $\begin{array}{c}4.444 \times 10- \\
4\end{array}$ & NS & $\begin{array}{c}1.212 \times 10 \\
-5\end{array}$ & $\begin{array}{c}1.974 \times 10 \\
-4\end{array}$ & $\begin{array}{c}5.121 \times 10 \\
-4\end{array}$ & $\begin{array}{c}1.691 \times 10 \\
-4\end{array}$ \\
\hline \multicolumn{9}{|l|}{ DNA $\beta$ (Betasatellite) } \\
\hline $1167-56$ (SCR) & $\begin{array}{l}\text { ToLCPnB-[IN:PUSA } \\
\text { 1:10].HQ180393 }\end{array}$ & $\begin{array}{l}\text { ToLCBDB[IN:Bih9:10].GU7 } \\
32208\end{array}$ & $\begin{array}{c}5.919 \times 10- \\
14\end{array}$ & $\begin{array}{c}2.521 \times 10 \\
-6\end{array}$ & $\begin{array}{c}3.53 \times 10- \\
7\end{array}$ & $\begin{array}{c}7.86 \times 10- \\
9\end{array}$ & $\begin{array}{c}6.542 \times 10 \\
-12\end{array}$ & $\begin{array}{c}1.114 \times 10 \\
-12\end{array}$ \\
\hline 89-758 (BC1) & ToLCJoB[IN:Kal:Pep:06] .EF190216 & $\begin{array}{c}\text { ToLCJoB- } \\
\text { [IN:Kal:Tom:08].JN176566 }\end{array}$ & $\begin{array}{c}8.195 \times 10- \\
3\end{array}$ & $\begin{array}{c}1.483 \times 10 \\
-2\end{array}$ & $\begin{array}{c}1.189 \times 10 \\
-6\end{array}$ & NS & $\begin{array}{c}4.102 \times 10 \\
-8\end{array}$ & $\begin{array}{c}5.348 \times 10 \\
-5\end{array}$ \\
\hline
\end{tabular}

NS- Recombination is non-significance

Definition for acronyms of begomviruses, betasatellite and alphasatellite given in the supplementary Table 1-3

${ }^{\text {a }}$ The text in the parenthesis of this column indicates ORF's in which break points are identified 